\title{
Automated VHF-Radio Telemetry Reveals Resource- Driven Site Utilisation Patterns in a Small-Bodied, Highly Mobile Bird (Erythrura Gouldiae)
}

Brittany K Hayward-Brown ( $\sim$ brittany.haywardbrown@gmail.com )

Charles Darwin University https://orcid.org/0000-0002-2367-7095

Tara L Crewe

Government of Nova Scotia

Sydney J Collett

Charles Darwin University Research Institute for the Environment and Livelihoods

Vinay Udyawer

Australian Institute of Marine Science

lan J Radford

Western Australia Department of Biodiversity Conservation and Attractions

Mariana A Campbell

Charles Darwin University Research Institute for the Environment and Livelihoods

Hamish A Campbell

Charles Darwin University Research Institute for the Environment and Livelihoods

\section{Research}

Keywords: passive tracking, automated radio telemetry, resource use, optimal foraging theory, behavioural flexibility

Posted Date: December 20th, 2021

DOl: https://doi.org/10.21203/rs.3.rs-1165860/v1

License: @ (i) This work is licensed under a Creative Commons Attribution 4.0 International License. Read Full License 


\section{Abstract}

\section{Background}

Information on site utilisation and movement is essential for managing species' resource requirements. Collecting these data requires frequent location sampling of multiple individuals, which can be challenging for small-bodied animals due to the often-large size of animal-borne satellite-based telemetry devices. We show how coded VHF-radio nano-transmitters and an array of passive receivers to collect location data at sufficient frequency and accuracy can be utilised to test whether the highly mobile and small-bodied Gouldian finch adheres to optimal foraging theory within a landscape of high spatiotemporal heterogeneity.

\section{Methods}

Coded VHF-radio nano-transmitters (0.23 g wt.) were attached to 38 Gouldian finches (Erythrura gouldiae; < $12 \mathrm{~g}$ bd. wt). Tagged birds were then detected by an array of 6 passive VHF-radio receivers ( $\sim 530 \mathrm{~m}$ detection range) spread over $120 \mathrm{~km}^{2}$. We tracked the tagged birds during two sessions corresponding with high and low abundance of their primary food resource (Sorghum spp. seed). The mean and total duration that an individual spent within any receiver detection field (residence time) were used as dependants in a generalised linear mixed model approach within a Bayesian framework to assess the influence of tracking session, life stage, receiver site, and release site. Network analysis revealed the importance of specific areas for the finches within the receiver array using the proportional time a bird spent within any receiver's detection field and the movement between adjacent detection fields.

\section{Results}

The daily mean and total duration that a tagged individual spent within a receiver detection field decreased by $\sim 50 \%$ between periods of high and low seed availability, while the extent of movements across the landscape increased with a decline in seed resources. These data support the hypothesis that the Gouldian finch adheres to optimal foraging theory to survive periods of food scarcity.

\section{Conclusions}

The data collected via passive telemetry technology support the hypothesis that the Gouldian finch adheres to optimal foraging theory and uses alternative behavioural strategies to survive periods of food scarcity. Specifically, we found that Gouldian finches reduced the time spent foraging within a patch, increased the frequency of transit flights among patches, and expanded the size of their activity space as grass resources declined.

\section{Background}

Understanding the drivers of animal space utilisation and habitat connectivity is a key aspiration of Movement Ecology (1). The data for determining these ecological traits in free-ranging animals is often collected using animal-borne biotelemetry devices. Telemetry devices that log the animal's location on the earth's surface using satellites for either location or data transfer are probably the most popular (2). However, 
satellite telemetry is not suitable for a significant number of species, and alternative methods need to be developed to determine an individual's location (3).

Passive node-based tracking technologies have been gaining popularity as an alternative to satellite transmitters $(4,5)$. These technologies offer the advantage of tracking animals that live their lives underwater or for small-bodied terrestrial animals. Passive tracking technology uses an animal-borne transmitter and an array of static receivers deployed in a specified formation. Each transmitter emits a uniquely coded pulse on a single frequency, ranging from VHF (very high frequency) to sonic wavelengths. The transmissions tend to be frequent (less than 1 min intervals), and the date and time of signal arrival are logged by a receiver when the transmitter is within range. This design allows for high-frequency location tracking of multiple individuals simultaneously within the array's boundaries (4). Over the last two decades, the technology has primarily been developed and used to track aquatic animals $(5,6)$, but a growing number of terrestrial applications have emerged in recent years $(7,8)$. However, there remains a disparity in data synthesis between terrestrial and aquatic passive telemetry applications. In the aquatic environment, passive telemetry is commonly used to estimate site utilisation, habitat connectivity, and the size of the activity space (5,9-12), whereas, in terrestrial environments, the application is still predominantly focused upon only collecting presence or absence information $(4,13-15)$.

Here, we trialled miniaturised coded VHF-radio transmitters and an array of passive receivers to monitor the granivorous Gouldian finch's fine-scale movements and site occupancy (Erythrura gouldiae) in the Australian tropical savannas. Grass finches are too small-bodied ( $<12 \mathrm{~g}$ body wt.) to allow for the attachment of even the most miniature satellite or GPS-based device with sufficient power to obtain frequent location fixes over reasonable durations. The finches are highly mobile and unpredictable as they move across the remote landscape of north Australian tropical savannas to collect grass seed. Multiple teams' active tracking attempts have proven unsuccessful in collecting the necessary data to assess site utilisation and patch use $(16,17)$.

The tropical savannas of north Australia are highly seasonal in the abundance of food resources. Grasses are the primary producers in these landscapes and boom after the wet season rains, leading to seed abundance in the late wet and early dry seasons (18-21). As the dry season progresses, the grasses dry out, and the subsequent broad-scale grass fires are common (22). Extensive and high-intensity fires, typical of contemporary fire regimes, denude the landscape and burn remaining grass seed stock, resulting in an environment poor in primary producer resources until the rains return the following year $(20,23)$. This boombust cycle is predictable, and the species that persist within tropical savannas have adopted effective strategies to survive these low resource periods (24). Previous studies have suggested that obligate granivorous birds are nomadic and move throughout the landscape to track grass seed patches $(16,17,21,25-$ 29). This study aimed to test the hypothesis that Gouldian finches will reduce the time spent foraging within a patch, increase the frequency of transit flights between patches, and expand the size of their activity space as grass resources decline (i.e., adhere to optimal foraging (30). Because location data collected by passive telemetry suffers from temporal autocorrelation stemming from repeated measures of an individual at a specific receiver in the array (10,31-34), we applied Bayesian statistics and network analysis to the data to reveal site utilisation and connectivity (35). The study provides a replicable methodology that allows 
researchers to investigate fine to mesoscale movements and site utilisation in highly mobile and small-bodied vertebrates.

\section{Methods}

\section{Study area}

This study was conducted in the East Kimberley region of Western Australia (Fig. 1). The climate is characterised by a distinct wet and dry season (36), with the study being conducted throughout the dry season (May and October) when little to no rainfall occurs $(0-21.8 \mathrm{~mm})(36,37)$. The habitat is tropical savanna woodland with an understory dominated by a mix of annual and perennial grasses (37-39). The substantial seasonal variation in rainfall drives the flowering and seeding patterns of the grasses and the incidence and extent of fire $(16,22,40)$.

\section{Bird capture and transmitter attachment}

Thirty-eight Gouldian finches (Erythrura gouldiae) were captured and tagged in July and October 2019. Trapping occurred at two locations approximately $11 \mathrm{~km}$ apart. The birds were captured using mist-nets $(12 \mathrm{~m}$ length, $2.7 \mathrm{~m}$ height, $25 \mathrm{~mm}$ mesh) placed strategically around waterholes so that the birds flew into the nets as they flew off after drinking. The nets were opened at approximately 0600 and set for two to three hours. Trapping effort between locations was approximately equal (See Supplementary Table 1, Additional File 1).

Each bird was sexed and classified as adult or juvenile upon capture based on plumage. The lack of distinctive colour differences in juveniles meant that sex could not be determined at this life stage. Each bird was banded with an identifiable size 2 aluminium ABBBS (Australian Bird and Bat Banding Scheme) leg-band. Individuals over $11 \mathrm{~g}$ were fitted with a $0.21 \mathrm{~g}$ NTQB2-2 avian coded VHF nanotag (Lotek Wireless Inc.), using a figure-8 leg loop harness made of cotton-coated elastic thread (Fig. 2a.; 47). The tags weighed less than $3 \%$ of the smallest individual's body weight. The harness degraded in the sun, and the transmitter detached from the bird between $30-80$ days after attachment. This tag attachment method allowed for unimpeded flight and growth in juveniles (41). The transmitters had an estimated battery life of 130 days, utilising a $12 \mathrm{~h}$ on/off cycle to preserve battery life. The transmitters were off between $5 \mathrm{pm}$, and 5 am as the birds were unlikely to be feeding during these periods.

\section{Autonomous VHF telemetry}

The deployed nanotags transmitted pulses on the same frequency $(151.5 \mathrm{MHz})$, with each transmitter generating a uniquely coded pulse every $11-13$ seconds $(4,15)$. The tag transmissions were then subsequently detected on six automated VHF receivers deployed across an area of $120 \mathrm{~km}^{2}$ (Fig. 1). The receivers were placed based upon prior knowledge of Gouldian finch occurrence (38-40,42-44). Each receiver was composed of a $3.3 \mathrm{~m}$ omni-directional VHF collinear antenna (151-152 MHz, $5.1 \mathrm{dBi}$ ) mounted on a $5.25 \mathrm{~m}$ aluminium post (Fig. 2b). The receivers comprised a Nooelec NESDR SMArTee RTL-SDR radio dongle connected to a Raspberry Pi 3 computer processor with Sensorgnome software (https://sensorgnome.org/) and an Adafruit Ultimate GPS Hat for time synchronisation. Each receiver listened continuously for the 
transmitters at $151.5 \mathrm{MHz}$ and was powered using a $12 \mathrm{~V}$ deep-cycle battery, continually charged by a $100 \mathrm{~W}$ solar panel.

\section{Data preparation}

Detection data were downloaded manually from each receiver, collated into a single dataset, and then processed to define the unique transmitter codes using the Motus Wildlife Tracking System (Motus motus.org (4)). Detections within 48 hours from release (acclimation period), with a run-length < 4 (false detections; (15)), and with > 40 days post-release (preventing cross-over between tracking sessions) were removed for final data analysis. Due to the overlapping detection ranges of receivers, we removed detections with a signal strength greater than $-45 \mathrm{~Hz}$ to limit the detection radius of receivers to $529.78 \pm 0.001 \mathrm{~m}$ (See Supplementary Fig. 1, 2, Table 1, Additional File 1) and prevent the likelihood of simultaneous transmitter detections across multiple receivers; this allowed receivers to be considered independent for this study. We then used this presence/absence data to determine residency and movement patterns metrics.

\section{Data Analysis}

\section{Assessing site occupancy}

We used the VTrack v. 1.21 package in $\mathrm{R} v$ 4.0.0 $(45,46)$ to determine the time each bird's spent inside and outside each receiver's detection range. We determined the duration that a bird spent in any receiver's detection range by taking the time between first and last detection. If the time between detections were greater than 30 minutes, this would trigger a new residence event. By choosing a 30-minute timeout period, we increased the resolution of the data, capturing the fine temporal scale movement of Gouldian finches targeted by this study (See Supplementary Fig. 3, Additional File 1). This filtered data was used to calculate mean and total daily residence time per tagged individual per receiver per day as a measure of daily flight activity and site occupancy, respectively.

Using the residence log produced by $V$ Track, we tested the variation in total and mean residence time (bird per receiver per day) using a generalised linear mixed model approach within a Bayesian analysis framework with Integrated Nested Laplace Approximation (INLA) methodology (47) in R v. 4.0.0 (46). Explanatory variables included tracking session (1 for early or 2 for late dry season), the life stage of a bird (adult or juvenile), release site (A or $B)$, and receiver site $(1-6)$. We conducted initial data exploration following the protocol described in Zuur, leno \& Elphick (48). A gamma data distribution was fitted to the data to account for leftskewed, overdispersed data. Bird identity and day of detection (Julian) for each tagged bird (nested) were included as Gaussian and first-order autoregressive random effects, respectively, ensuring we accounted for the effect of repeated measures on the same individual and temporal autocorrelation among detection days for a given individual. Penalised Complexity (PC) priors were used for the random effect marginal distributions, using the standard error of the response variable, following Simpson et al. (49)

Model selection using deviance information criterion (DIC) was applied to identify those covariates important to the data (See Supplementary Table 3, Additional File 1). We then undertook model validation to identify the final models' underlying assumptions, including homogeneity of residual variance, by plotting Pearson residuals versus fitted values and against each covariate $(48,50)$ (See Supplementary Fig. 4 -8, Additional File 
1). The mean, standard deviation, and $0.025-0.975$ quantiles (posterior distribution) were obtained for each covariate in the top-ranked model and models within a $\triangle \mathrm{DIC}$ of 2 . The generation of $0.025-0.975$ quantiles allowed probability statements to be made about whether the unknown parameter was $95 \%$ likely to fall within the range of given values (34). If the confidence intervals encompassed zero, an effect of the covariate on the response was not strongly supported by the data.

\section{Assessing site connectivity}

Network analysis was performed to address the hypothesis that Gouldian finches would expand activity space in response to the seasonal decline in resources and explore connectivity between receiver sites. Network analysis is based on graph theory, which uses pairwise interactions of nodes linked by edges to present graphical representations of network structure $(34,35,51)$. Node-based metrics, such as eigenvector centrality, can identify critical areas of importance within the network and measure connectivity $(35,52)$. The network in this study was constructed using the residence and non-residence event logs generated in VTrack. The nodes were populated by the time a bird spent within a given receiver's detection range as a proportion of the total time spent within the receiver array. The edges were populated by the frequency of movement between receiver detection ranges. The event information was analysed using the package igraph (53) in R (46). The eigenvector centrality metric in igraph was then used to calculate which receivers were most central within the network (35), and the node and edge values were quantified and compared to determine which receivers and pathways between receivers were utilised frequently between and among tracking sessions.

\section{Results}

\section{Finch capture and tracking}

A total of 283,715 detections were collected from 15 adult and 23 juvenile Gouldian finches monitored during tracking sessions 1 (July-August) and 2 (October-November). Tagged birds were captured and subsequently released at sites A or B (Fig. 1.) and detected for a period of 4 to 39 Julian days in either session 1 or 2 . The mean and total time a tagged Gouldian finch spent within the detection range of any given receiver were lower in session 2 compared to session 1 (Table 1). Gouldian finches were not captured at Site B in session 1 (Table 1; See Supplementary Table 1, Additional File 1).

Table 1

Residency information for 38 tagged Gouldian finches within the detection range of the receiver array.

\begin{tabular}{|c|c|c|c|c|c|c|c|c|}
\hline Session & $\begin{array}{l}\text { Release } \\
\text { site (A) } \\
\text { (n. } \\
\text { birds) }\end{array}$ & $\begin{array}{l}\text { Release } \\
\text { site (B) } \\
\text { (n. } \\
\text { birds) }\end{array}$ & $\begin{array}{l}\text { Life } \\
\text { stage } \\
\text { (Adult) } \\
\text { (n. } \\
\text { birds) }\end{array}$ & $\begin{array}{l}\text { Life stage } \\
\text { (Juvenile) } \\
\text { (n. birds) }\end{array}$ & $\begin{array}{l}\text { Detection } \\
\text { days (n) }\end{array}$ & $\begin{array}{l}\text { Residence } \\
\text { events } \\
\text { (n) }\end{array}$ & $\begin{array}{l}\text { Mean } \\
\text { residence } \\
\text { time } \\
\text { (min) }\end{array}$ & $\begin{array}{l}\text { Total } \\
\text { residence } \\
\text { time } \\
\text { (min) }\end{array}$ \\
\hline 1 & 19 & 0 & 5 & 14 & $\begin{array}{l}24.31 \pm \\
13.74\end{array}$ & $\begin{array}{l}73.32 \pm \\
45.12\end{array}$ & $\begin{array}{l}151.61 \pm \\
38.66\end{array}$ & $\begin{array}{l}1455.37 \\
\pm 484.15\end{array}$ \\
\hline 2 & 9 & 10 & 10 & 9 & $\begin{array}{l}21.63 \pm \\
9.25\end{array}$ & $\begin{array}{l}39.32 \pm \\
28.09\end{array}$ & $\begin{array}{l}83.69 \pm \\
50.07\end{array}$ & $\begin{array}{l}623.69 \pm \\
496.65\end{array}$ \\
\hline
\end{tabular}

Detection days is the mean number of Julian days over which a tagged bird was detected. Residence events are the mean number of times a tagged bird was detected over the tracking period. Mean and total residence 
times are the mean and total duration of time a tagged bird was detected on a given day within the array.

\section{Site Occupancy}

Table 2

Top-ranked models for ranked mean and total duration of residence events per individual/day

\begin{tabular}{|c|c|c|c|}
\hline Metric & Model & $\begin{array}{l}\text { No. of } \\
\text { parameters }\end{array}$ & $\Delta \mathrm{DIC}$ \\
\hline \multirow{7}{*}{$\begin{array}{l}\text { Mean duration of residence event } \\
\text { day/individual/receiver (minutes) }\end{array}$} & Session & 107.92 & 0.00 \\
\hline & Session + Life stage & 108.39 & 0.03 \\
\hline & Session* Life stage & 108.89 & 0.46 \\
\hline & Session* Release site & 106.3 & 0.66 \\
\hline & Session + Release site & 106.7 & 0.86 \\
\hline & $\begin{array}{l}\text { Session }+ \text { Life stage + } \\
\text { Release site }\end{array}$ & 107.21 & 0.95 \\
\hline & Life stage & 110.67 & 1.74 \\
\hline \multirow{7}{*}{$\begin{array}{l}\text { Total duration of residence } \\
\text { events/day/individual/receiver (minutes) }\end{array}$} & Life stage & 97.12 & 0 \\
\hline & Session & 95.72 & 0.611697 \\
\hline & $\begin{array}{l}\text { Session + Life stage + } \\
\text { Receiver }\end{array}$ & 95.47 & 0.636675 \\
\hline & Session + Life stage & 96.48 & 0.830925 \\
\hline & Session * Life stage & 96.81 & 1.058068 \\
\hline & Session + Receiver & 95.91 & 1.152467 \\
\hline & Receiver & 95.43 & 1.920348 \\
\hline
\end{tabular}

DIC model selection supported both session and life stage effects in the two top competing models (Table 2). However, the addition of life stage did not add substantial explanatory power (Table $2 ; \Delta D I C \geq 0.03$ ) to the model with session only, and confidence limits for the effect of life stage included zero (Table 3). Together, this suggests the data do not strongly support an effect of life stage on mean residence time. The top-ranked model, which included only the effect of session, showed strong support (95\% CL that excluded 0; Table 3) for a decline in mean residence time from session 1 (mean (95\% CL): 64.8 mins $(54.6,79.1)$; Fig. 3), to session 2 (mean (95\% CL): 35.1 mins (29.5,41.2); Fig. 3). Release site received support in two competing models ( $\triangle \mathrm{DIC}$ $=0.86,0.95)$, with the confidence limits for the estimate for site A positive and above zero (Table 2,3$)$. These results may be an artefact of the greater number of birds released at site $A$ than site $B$ in session 1 and overall between sessions (Table 1; See supplementary Table 1., Additional File 1). However, the model that tested 
whether the effect of release site varied with session (session * release site interaction; $\Delta \mathrm{DIC}=0.66$, Table 2 , 3 ) did not support an effect of release site or the interaction, with confidence limits excluding zero (Table 3 ).

Table 3

Posterior mean, standard deviation and $95 \%$ confidence limits of covariates in models within $\triangle \mathrm{DIC}$ of 2 of the top-ranked model for mean residence event duration for an individual/day

\begin{tabular}{|c|c|c|c|c|c|c|}
\hline Model & $\Delta \mathrm{DIC}$ & Covariate & $\begin{array}{l}\text { Posterior } \\
\text { mean }\end{array}$ & $\begin{array}{l}\text { Posterior } \\
\text { SD }\end{array}$ & $\begin{array}{l}\text { Lower } \\
\text { CL }\end{array}$ & $\begin{array}{l}\text { Upper } \\
\text { CL }\end{array}$ \\
\hline \multirow[t]{2}{*}{ Session } & \multirow[t]{2}{*}{0} & (Intercept) & 4.18 & 0.08 & 4.01 & 4.34 \\
\hline & & Session (2) & -0.61 & 0.12 & -0.85 & -0.38 \\
\hline \multirow{3}{*}{$\begin{array}{l}\text { Session + } \\
\text { Life stage }\end{array}$} & \multirow[t]{3}{*}{0.03} & (Intercept) & 4.18 & 0.08 & 4.02 & 4.35 \\
\hline & & Session (2) & -0.62 & 0.11 & -0.85 & -0.40 \\
\hline & & Life stage (Adult) & 0.08 & 0.11 & -0.14 & 0.31 \\
\hline \multirow[t]{4}{*}{ Session * Life stage } & \multirow[t]{4}{*}{0.46} & (Intercept) & 4.16 & 0.10 & 4.36 & 4.16 \\
\hline & & Session (2) & -0.69 & 0.16 & -1.02 & -0.36 \\
\hline & & Life stage (Adult) & 0.04 & 0.19 & -0.32 & 0.42 \\
\hline & & $\begin{array}{l}\text { Session (2)* Life } \\
\text { stage (Adult) }\end{array}$ & 0.12 & 0.26 & -0.40 & 0.62 \\
\hline \multirow[t]{4}{*}{ Session * Release site } & \multirow[t]{4}{*}{0.66} & (Intercept) & 3.79 & 18.26 & -32.05 & 39.61 \\
\hline & & Session (2) & -0.39 & 18.26 & -36.24 & 35.42 \\
\hline & & Release site (A) & 0.39 & 18.26 & -35.46 & 36.20 \\
\hline & & $\begin{array}{l}\text { Session }(2) \text { * Release } \\
\text { site }(A)\end{array}$ & -0.01 & 18.26 & -35.85 & 35.81 \\
\hline \multirow[t]{3}{*}{ Session + Release site } & \multirow[t]{3}{*}{0.86} & (Intercept) & 3.80 & 0.17 & 3.47 & 4.14 \\
\hline & & Session (2) & -0.40 & 0.14 & -0.68 & -0.14 \\
\hline & & Release site (A) & 0.38 & 0.15 & 0.068 & 0.97 \\
\hline \multirow{4}{*}{$\begin{array}{l}\text { Session + Life stage + } \\
\text { Release site }\end{array}$} & \multirow[t]{4}{*}{0.95} & (Intercept) & 4.2 & 0.10 & 4.00 & 4.39 \\
\hline & & Session (2) & -0.61 & 0.14 & -0.88 & -0.33 \\
\hline & & Life stage (Adult) & 0.06 & 0.11 & -0.16 & 0.30 \\
\hline & & Release site (A) & 0.36 & 0.16 & 0.04 & 0.67 \\
\hline \multirow[t]{2}{*}{ Life stage } & \multirow[t]{2}{*}{1.74} & (Intercept) & 3.90 & 0.11 & 3.68 & 4.13 \\
\hline & & Life stage (Adult) & -0.07 & 0.17 & -0.41 & 0.28 \\
\hline
\end{tabular}




\section{Total daily residence time (a measure of site occupancy)}

DIC model selection supported the effects of session, life stage and receiver in the three top competing models (Table 2). However, across these models, the data supported only session and receiver, with confidence limits that excluded zero (Table 4). An effect of life stage on total residence time did not receive strong support in any model within $\triangle \mathrm{DIC}$ of 2 (95\% CL included zero: Table 4). Due to the lack of importance of life stage as an effect, the model, which included session and receiver, was used for inference and plot model predictions. The final model showed strong support for (95\% CL that excluded zero; Table 4) a decline in total residence time between session 1 (mean (95\% CL): 153 mins $(122,189)$ ), to session 2 (mean (95\% CL): 65.4 mins $(46.2,89.6)$ ) (Fig. 4a). Total residence time also differed among receiver sites, longest at receiver 2 (mean (95\% CL): 148 mins $(117,183)$ ), compared with receiver 3 (mean (95\% CL): 122 mins $(93.7,156)$ ), 1 (mean (95\% CL): 68.2 mins $(31.3,130)$ ), 4 (mean (95\% CL): 28.8 mins $(15.3,49.5)$ ), 5 (mean (95\% CL): 90.5 mins $(37.2,185))$, and 6 (mean $(95 \% \mathrm{CL})$ : 37 mins $(27.9,48.1))$ (Fig. 4b). The confidence limits for receivers 2 , 4, 5 and 6 excluded zero in the final model, showing strong support that total residence time varied by receiver and from the intercept (receiver 1; Table 4). 
Table 4

Posterior mean, standard deviation, and $95 \%$ confidence limits of covariates in models within $\Delta \mathrm{DIC}$ of 2 of the top-ranked models for total durations of all residence events for an individual/day

\begin{tabular}{|c|c|c|c|c|c|c|}
\hline Model & $\Delta \mathrm{DIC}$ & Covariate & $\begin{array}{l}\text { Posterior } \\
\text { mean }\end{array}$ & $\begin{array}{l}\text { Posterior } \\
\text { SD }\end{array}$ & $\begin{array}{l}\text { Lower } \\
\mathrm{CL}\end{array}$ & $\begin{array}{l}\text { Upper } \\
\text { CL }\end{array}$ \\
\hline \multirow[t]{2}{*}{ Life stage } & 0 & (Intercept) & 4.53 & 0.18 & 4.18 & 4.88 \\
\hline & & Life stage (Adult) & -0.14 & 0.28 & 0.41 & -0.14 \\
\hline \multirow[t]{2}{*}{ Session } & 0.61 & (Intercept) & 5.00 & 0.14 & 4.71 & 5.27 \\
\hline & & Session (2) & -1.00 & 0.20 & -1.39 & -0.60 \\
\hline \multirow{8}{*}{$\begin{array}{l}\text { Session + Life stage + } \\
\text { Receiver }\end{array}$} & 0.64 & (Intercept) & 4.86 & 0.14 & 4.58 & 5.12 \\
\hline & & Session (2) & -0.50 & 0.20 & -0.90 & -0.11 \\
\hline & & Life stage (Adult) & 0.05 & 0.16 & -0.26 & 0.37 \\
\hline & & Receiver (2) & 0.21 & 0.09 & 0.03 & 0.21 \\
\hline & & Receiver (1) & -0.65 & 0.34 & -1.27 & -0.69 \\
\hline & & Receiver (6) & -0.78 & 0.23 & -1.22 & -0.79 \\
\hline & & Receiver (4) & -1.09 & 0.34 & -1.74 & -1.11 \\
\hline & & Receiver (5) & 0.05 & 0.44 & -0.80 & 0.04 \\
\hline \multirow[t]{3}{*}{ Session + Life stage } & 0.83 & (Intercept) & 4.96 & 0.16 & 4.65 & 4.96 \\
\hline & & Session (2) & -1.03 & 0.21 & -1.44 & -0.61 \\
\hline & & Life stage (Adult) & 0.12 & 0.21 & -0.30 & 0.54 \\
\hline \multirow[t]{4}{*}{ Session * Life stage } & 1.06 & (Intercept) & 5.00 & 0.17 & 5.33 & 5.00 \\
\hline & & Session (2) & -1.12 & 0.27 & -1.65 & -0.57 \\
\hline & & Life stage (Adult) & -0.01 & 0.32 & -0.63 & 0.63 \\
\hline & & $\begin{array}{l}\text { Session (2) * Life } \\
\text { stage (Adult) }\end{array}$ & 0.22 & 0.43 & -0.63 & 1.06 \\
\hline \multirow[t]{6}{*}{ Session + Receiver } & 1.15 & (Intercept) & 4.87 & 0.12 & 4.63 & 5.11 \\
\hline & & Session (2) & -0.47 & 0.19 & -0.85 & -0.11 \\
\hline & & Receiver (2) & 0.21 & 0.09 & 0.39 & 0.21 \\
\hline & & Receiver (1) & -0.64 & 0.34 & 0.07 & -0.69 \\
\hline & & Receiver (6) & -0.80 & 0.22 & -0.35 & -0.81 \\
\hline & & Receiver (4) & -1.11 & 0.34 & -0.43 & -1.13 \\
\hline
\end{tabular}

The final model used and important covariates are in bold. 


\begin{tabular}{|c|c|c|c|c|c|c|}
\hline Model & $\Delta \mathrm{DIC}$ & Covariate & $\begin{array}{l}\text { Posterior } \\
\text { mean }\end{array}$ & $\begin{array}{l}\text { Posterior } \\
\text { SD }\end{array}$ & $\begin{array}{l}\text { Lower } \\
\mathrm{CL}\end{array}$ & $\begin{array}{l}\text { Upper } \\
\text { CL }\end{array}$ \\
\hline & & Receiver (5) & 0.02 & 0.43 & 0.87 & 0.01 \\
\hline \multirow[t]{6}{*}{ Receiver } & \multirow[t]{6}{*}{1.92} & (Intercept) & 4.72 & 0.12 & 4.49 & 4.95 \\
\hline & & Receiver (2) & 0.21 & 0.09 & 0.03 & 0.39 \\
\hline & & Receiver (1) & -0.64 & 0.34 & -1.26 & 0.08 \\
\hline & & Receiver (6) & -1.12 & 0.20 & -1.49 & -0.74 \\
\hline & & Receiver (4) & -1.41 & 0.32 & -2.01 & -0.76 \\
\hline & & Receiver (5) & -0.16 & 0.44 & -1.01 & -0.72 \\
\hline
\end{tabular}

\section{Site connectivity}

During session 1, tagged birds spent proportionally more time at receivers 2 and 3 out of the entire array ( 0.77 and 0.27 respectively; See Supplementary Table 4, Additional File 1), coupled with a high number of connections between these adjacent receivers (111.5 \pm 0.71 ; see supplementary information Table S4). Fewer connections existed between receivers 2 and 3 and the other receivers (frequency $<6$ ). No connections were recorded between receiver 5 and any other receivers in session 1 (Fig. $5 \mathrm{a}, \mathrm{b}$ ). The network was considerably different during session 2. Tagged birds spent the highest proportion of time at receivers 2 and 6 out of the entire array ( 0.71 and 0.95 , respectively; See Supplementary Table 4, Additional File 1$)$. While the number of connections between receivers was reduced overall in session 2 compared to session 1, receivers 2 and 3 continued to have a relatively greater number of connections than other pairs of receivers $(30 \pm 1.41)$. However, there were more connections between receivers 4 and 6 (10) and receivers 5 and 4 (5) compared to session 1. Other connections between pairs of receivers in session 2 were at a frequency of $<2$ (See Supplementary Table 5, Additional File 1). Node eigenvector centrality was highest at receivers 2 and 3 at 1.00 during both sessions (Fig. 5c, d; See Supplementary Table 4, Additional File 1).

\section{Discussion}

This study demonstrated the utility of a passive VHF-radio 'receivers' array for determining site occupancy and habitat connectivity of a highly mobile small-bodied bird. Our results showed that the Gouldian finch (Erythrura gouldiae) adhered to Optimal Foraging Theory to best utilise the decline in Sorghum spp. seed that occurs throughout the dry season $(20,21,40)$. Optimal foraging theory was demonstrated by individuals reducing the time spent within a patch and increasing the rate of movements among patches as the dry season progressed and seed resources declined. The application of passive telemetry to understand localised behaviours is well established for aquatic animals (5), whilst in the terrestrial realm, this type of animal telemetry is predominately used to collect broad-scale migratory movements $(4,13,14)$. 
Passive VHF-radio telemetry detected the presence or absence of Gouldian finches continually and simultaneously as they free-ranged over a wide area. Whilst the location accuracy of each detection is less than a location fix derived from GPS-based telemetry, the high frequency of detections (every $11-13 \mathrm{~s}$ ) enabled us to define movement patterns and site utilisation at fine temporal scales. The low recapture rates for Gouldian finches in mark-recapture studies have led to suggestions of high mortality of the species in the late dry season $(17,28)$. However, we argue that the high increase in flight activity and enlarging of the activity space exhibited by the tagged birds in the late dry season may contribute to low recapture rates during the late dry season.

A criticism of passive tracking methods is that static receivers have a limited detection range, and tagged animals may occupy areas outside the array's detection range (54). Therefore, receiver volume and placement can influence the study findings (55). In the present study, receivers were strategically placed across the landscape in areas previously documented as occupied by Gouldian finches. Whilst we acknowledge that the tagged finches occupied areas outside the detection range of the array, the mean time a tagged bird spent within any detection area was a relative measure of individual activity. Likewise, the total time a bird spent within any detection area within a day was a relative measure of site fidelity. The network analysis supported these observations by showing that the tagged birds moved over a greater extent and undertook less repeated short flights when food resources were scarce.

To illustrate how a tagged birds behaviour resulted in the observed detection pattern, we have provided a schematic model Figure 6 . Concept A demonstrates behaviour in the mid dry season when resources were relatively abundant; the individual spends prolonged periods within a patch and infrequently moves between alternate patches, generating a high mean and total residence time in that receivers' detection field. Concept $\mathrm{B}$ demonstrates behaviour during a period of resource restriction; the individual spent short periods within a patch and frequently moved between alternate patches, generating a low mean and total residence time in any one detection field.

Figure 6. Schematic representation of the two different movement behavioural scenarios provided by the mean or total residence times measures within receiver detection ranges (circles). Mid-dry season movement represented by; a.) High total residence time and high mean residence time indicate high site occupancy and reduced extent of the activity space. b.) Low total residence time and low mean residence time is indicative of low site occupancy and increased extent of the activity space

The integration of these two concepts provided an index of the tagged individuals' behavioural strategy and are supported by morphological and dietary studies. For example, the wing of the Gouldian finch is more adapted for long-distance flights than those of other tropical savanna finch species (Long-tailed finch Poephila acuticauda, Double-barred finch Taeniopygia bichenovii, and Crimson finch Neochmia phaeton) (56). Additionally, the Gouldian finch feeds exclusively upon grass seeds, whilst sympatric finch species (Longtailed finch $P$. acuticauda and Masked finch $P$. personata) have been shown to switch diet during periods of low grass seed availability (57). Consequently, the body condition of the Gouldian finch is directly correlated with the availability and nutritional quality of grass seeds across the landscape, and late dry season wildfires have been shown to have a greater impact upon the Gouldian finch physiological condition when compared to its sympatric finch species (28). 


\section{Conclusions}

Data collected via passive tracking can be challenging to statistically analyse compared to the uniform timestamped location sampling of GPS-based telemetry $(34,59)$. However, mixed-effects modelling techniques can overcome the constraints associated with the uncertainty around the influence of individual birds (repeated measures) and individual receivers (temporal autocorrelation) by incorporating random effect structures $(10,31-34,60)$. We argue that coded nano-VHF transmitters, an array of passive receivers e (which can be constructed at a relatively low cost (8)), offer great potential in assessing how mobile small-bodied animals move through the landscape and adapt to habitat heterogeneity.

\section{Abbreviations}

VHF

very high frequency

ABBBS

Australian Bird and Bat Banding Scheme

DIC

Deviance Information Criteria

\section{Declarations}

\section{Acknowledgements}

We thank the Balanggarra Rangers of the Balanggara Indigenous Protected Area and The Williams Family, Traditional Owners of Country where this work was conducted, for access to the land and support during the project implementation. We acknowledge and respect their continuing connection to the land and sea surrounding the study area. We thank Thomas Rasmussen for technical support, including assistance in designing and constructing the receivers, and Jan Lewis, Joanne Heathcote, John Rawsthorne, Richard Allen, Mark Conboy and Timon Van Asten for their assistance in the field.

\section{Author's contributions}

BKHB worked on collecting data in the field, undertook the data analysis, and completed most of the writing; SJC designed the study and methodology, collected data in the field, and assisted significantly with data analysis; TLC designed the study and methodology, collected data in the field, designed the statistical analysis component, significantly guided and assisted with the data analysis and assisted with paper writing; VU advised and assisted with the network analysis component; IJR worked on collecting data in the field; MAC assisted with data interpretation and paper writing; HAC contributed to the conception and design of the study, execution of field component, and paper writing. All authors provided comments and edits that have improved this manuscript.

\section{Funding}


This work was supported by Charles Darwin University, Save the Gouldian Fund, National Drones, World Wide Fund for Nature Australia, Department of Biodiversity, Conservation and Attractions (WA), and the Australian Research Council (Project ID: LP160101716).

\section{Availability of data and materials}

The datasets used and analysed during the current study are available from the corresponding author on reasonable request.

\section{Ethics approval and consent to participate}

This project involved the use of animal subjects. The capture and tagging of Gouldian Finches (Erythrura gouldiae) were approved by the Charles Darwin University Animal Ethics Committee (Project A17015) and under a Western Australia Department of Conservation, Biodiversity and Attractions Fauna Taking permit (Permit No. 08-001715-2). This study was also conducted under Australian Bird and Bat Banding Scheme project no. 545-9.

\section{Consent for publication}

Not applicable.

\section{Competing interests}

The authors declare that they have no competing interests.

\section{References}

1. Nathan R, Getz WM, Revilla E, Holyoak M, Kadmon R, Smouse PE, et al. A movement ecology paradigm movement research for unifying organismal research. Proceedings of the National Academy of Sciences of the United States of America. 2008;105(49):19052-9.

2. Kays R, Crofoot MC, Jetz W, Wikelski M. Terrestrial animal tracking as an eye on life and planet. Science. 2015;348(6240):aaa2478.

3. Crossin GT, Heupel MR, Holbrook CM, Hussey NE, Lowerre-Barbieri SK, Nguyen VM, et al. Acoustic telemetry and fisheries management. Ecological Applications. 2017;27(4):1031-49.

4. Taylor PD, Crewe TL, Mackenzie SA, Lepage D, Aubry Y, Crysler Z, et al. The motus wildlife tracking system: A collaborative research network to enhance the understanding of wildlife movement. Avian Conservation and Ecology. 2017;12(1).

5. Hussey NE, Kessel ST, Aarestrup K, Cooke SJ, Cowley PD, Fisk AT, et al. Aquatic animal telemetry: A panoramic window into the underwater world. Science. 2015;348(6240):1255642.

6. Bridge ES, Thorup K, Bowlin MS, Chilson PB, Diehl RH, Fléron RW, et al. Technology on the Move: Recent and Forthcoming Innovations for Tracking Migratory Birds. BioScience. 2011;61(9):689-98.

7. Crewe TL, Kendal D, Campbell HA. Motivations and fears driving participation in collaborative research infrastructure for animal tracking. PLoS ONE. 2020;15. 
8. Griffin AS, Brown C, Woodworth BK, Ballard G, Blanch S, Campbell HA, et al. A large-scale automated radio telemetry network for monitoring movements of terrestrial wildlife in Australia. Australian Zoologist. 2019;40:379-91.

9. Brodie S, Lédée EJI, Heupel MR, Babcock RC, Campbell HA, Gledhill DC, et al. Continental-scale animal tracking reveals functional movement classes across marine taxa. Scientific Reports. 2018;8(1):1-9.

10. Udyawer V, Simpfendorfer CA, Read M, Hamann M, Heupel MR. Exploring habitat selection in sea snakes using passive acoustic monitoring and Bayesian hierarchical models. Marine Ecology Progress Series. 2016;546:249-62.

11. Lyon BJ, Dwyer RG, Pillans RD, Campbell HA, Franklin CE. Distribution, seasonal movements and habitat utilisation of an endangered shark, Glyphis glyphis, from northern Australia. Marine Ecology Progress Series. 2017;573:203-13.

12. Dwyer R, Campbell H, Cramp R, Burke C, Micheli-Campbell M, Pillans R, et al. Niche partitioning between river shark species is driven by seasonal fluctuations in environmental salinity. Functional Ecology. 2020;00:1-16

13. Woodworth BK, Mitchell GW, Norris DR, Francis CM, Taylor PD. Patterns and correlates of songbird movements at an ecological barrier during autumn migration assessed using landscape-and regionalscale automated radiotelemetry. Ibis: International Journal of Avian Science. 2014;157:326-339

14. Cooper NW, Marra PP. Hidden Long-Distance Movements by a Migratory Bird. Current Biology. 2020;30(20):4056-4062.e3.

15. Crewe TL, Deakin JE, Beauchamp AT, Morbey YE. Detection range of songbirds using a stopover site by automated radio-telemetry. Journal of Field Ornithology. 2019;90(2):176-89.

16. Dostine PL, Johnson GC, Franklin DC, Zhang Y, Hempel C. Seasonal use of savanna landscapes by the Gouldian finch, Erythrura gouldiae, in the Yinberrie Hills area, Northern Territory. Wildlife Research. 2001;28(4):445-58.

17. Woinarski JCZ, Tidemann S. Survivorship and Some Population Parameters for the Endangered Gouldian Finch Erythrura gouldiae and Two Other Finch Species at Two Sites in Tropical Northern Australia. Royal Australian Ornithologists Union. 1992;92:33-8.

18. Franklin DC, Woinarski JCZ, Noske RA. Geographical patterning of species richness among granivorous birds in Australia. Journal of Biogeography. 2000;27:829-842

19. Crowley G, Garnett S. Seeds of the annual grasses Schizachyrium spp. as a food resource for tropical granivorous birds. Australian Journal of Ecology. 1999;24:208-20.

20. Andrew MH, Mott JJ. Annuals with transient seed banks: the population biology of indigenous Sorghum species of tropical north-west Australia. Australian Journal of Ecology. 1983;8:265-276

21. Woinarski JCZ, Tidemann SC. The bird fauna of a deciduous woodland in the wet-dry tropics of northern Australia. Wildlife Research. 1991;18(4):479-500.

22. Russell-Smith J, Yates C, Edwards A, Allan GE, Cook GD, Cooke P, et al. Contemporary fire regimes of northern Australia, 1997-2001: Change since Aboriginal occupancy, challenges for sustainable management. International Journal of Wildland Fire. 2003;12(3-4):283-97. 
23. Yates CP, Edwards AC, Russell-Smith J. Big fires and their ecological impacts in Australian savannas: size and frequency matters. International Journal of Wildland Fire. 2008;17(6):768-81.

24. Woinarski JCZ, Legge S. The impacts of fire on birds in Australia's tropical savannas. Emu. 2013;113(4):319-52.

25. Zann RA, Morton SR, Jones KR, Burley NT. The timing of breeding by zebra finches in relation to rainfall in central australia. Emu. 1995;95(3):208-22.

26. Woinarski JCZ. Predictors of nomadism in Australian birds: A reanalysis of Allen and Saunders (2002). Ecosystems. 2006;9(5):689-93.

27. Bolton PE, West AJ, Cardilini APA, Clark JA, Maute KL, Legge S, et al. Three molecular markers show no evidence of population genetic structure in the Gouldian finch (Erythrura gouldiae). PLoS ONE. 2016;11(12):e0167723-e0167723.

28. Legge S, Garnett S, Maute K, Heathcote J, Murphy S, Woinarski JCZ, et al. A landscape-scale, applied fire management experiment promotes recovery of a population of the threatened Gouldian finch, Erythrura gouldiae, in Australia's tropical savannas. PLoS ONE. 2015;10(10):e0137997.

29. Rechetelo J, Grice A, Reside AE, Hardesty BD, Moloney J. Movement patterns, home range size and habitat selection of an endangered resource tracking species, the black-throated finch (Poephila cincta cincta). PLoS ONE. 2016;11(11): e0167254

30. Maynard Smith J. Optimisation theory in evolution. Annual Review of Ecological Systems. 1978;9:31-56.

31. Johnson DS, London JM, Kuhn CE. Bayesian Inference for Animal Space Use and Other Movement Metrics. Journal of Agricultural, Biological and Environmental Statistics. 2011;16(3):357-370

32. Muff S, Signer J, Fieberg J. Accounting for individual-specific variation in habitat-selection studies: Efficient estimation of mixed-effects models using Bayesian or frequentist computation. Wal E vander, editor. Journal of Animal Ecology. 2020;89(1):80-92.

33. Alós J, Palmer M, Balle S, Arlinghaus R. Bayesian State-Space Modelling of Conventional Acoustic Tracking Provides Accurate Descriptors of Home Range Behavior in a Small-Bodied Coastal Fish Species. PLoS ONE. 2016;11(4):e0154089

34. Griffin L, Finn J, Diez C, Danylchuk A. Movements, connectivity, and space use of immature green turtles within coastal habitats of the Culebra Archipelago, Puerto Rico: implications for conservation. Endangered Species Research. 2019;40:75-90.

35. Jacoby DMP, Freeman R. Emerging Network-Based Tools in Movement Ecology. Trends in Ecology and Evolution. 2016;31(4):301-14.

36. Bureau of Meteorology. Climate statistics for Australian locations: Summary statistics Wyndham Port. http://www.bom.gov.au/climate/averages/tables/cw_001005.shtml. Accessed May 12020.

37. Radford IJ, Oliveira SLJ, Byrne B, Woolley L-A. Tree hollow densities reduced by frequent late dry-season wildfires in threatened Gouldian finch (Erythrura gouldiae) breeding habitat. Wildlife Research. 2021;48:511-520

38. Brazill-Boast J, Pryke S, Griffith SC. Nest-site utilisation and niche overlap in two sympatric, cavity-nesting finches. Emu. 2010;110(2):170-7. 
39. Weier A, Radford IJ, Manson A, Durrans LJ, Lawes MJ. Frequent fires reduce the nutritional quality of Sorghum stipoideum seed, a keystone food resource for the Gouldian finch (Erythrura gouldiae). Rangeland Journal. 2017;39(2):105-12.

40. Weier A, Radford IJ, Woolley L-A, Lawes MJ. Fire regime effects on annual grass seeds as food for threatened grass-finch. Fire Ecology. 2018;14(2):2-11.

41. Casper RM. Guidelines for the instrumentation of wild birds and mammals. Animal Behaviour. 2009;78(6):1477-1483

42. Brazill-Boast J, Dessmann JK, Davies GTO, Pryke SR, Griffith SC. Selection of breeding habitat by the endangered Gouldian finch (Erythrura gouldiae) at two spatial scales. Emu. 2011;111:304-11.

43. Weier A, Radford IJ, Oliveira SLJ, Lawes MJ. Recently but infrequently burnt breeding sites are favoured by threatened Gouldian finches (Erythrura gouldiae). International Journal of Wildland Fire. 2016;25(12):1281-90.

44. Weier A, Radford IJ, Bellairs SM, Lawes MJ. Seed set in Sorghum stipoideum, and not fire, determines the timing of breeding by Gouldian finches (Erythrura gouldiae). Austral Ecology. 2019;44(1):151-62.

45. Campbell, HA, Watts, ME, Dwyer, RG, Franklin CE. V-Track: software for analysing and visualising animal movement from acoustic telemetry detections. Marine and Freshwater Research. 2012;63(9);815-820

46. R Core Team. R: A language and environment for statistical computing. Vienna, Austria: R Foundation for Statistical Computing; 2020. Available from: https://www.R-project.org/

47. Rue H, Martino S, Chopin N. Approximate Bayesian Inference for Latent Gaussian Models by Using Integrated Nested Laplace Approximations. Source: Journal of the Royal Statistical Society Series B (Statistical Methodology). 2009;71:319-92.

48. Zuur AF, leno EN, Elphick CS. A protocol for data exploration to avoid common statistical problems. Methods in Ecology and Evolution. 2010;1(1):3-14.

49. Simpson D, Rue H, Riebler A, Martins TG, Sørbye SH. Penalising model component complexity: A principled, practical approach to constructing priors. Statistical Science. 2017;32:1-28.

50. Zuur AF, leno EN. A protocol for conducting and presenting results of regression-type analyses. Methods in Ecology and Evolution. 2016;7(6):636-45.

51. Jacoby DMP, Brooks EJ, Croft DP, Sims DW. Developing a deeper understanding of animal movements and spatial dynamics through novel application of network analyses. Methods in Ecology and Evolution. 2012;3(3):574-83.

52. Bastille-Rousseau G, Douglas-Hamilton I, Blake S, Northrup JM, Wittemyer G. Applying network theory to animal movements to identify properties of landscape space use. Ecological Applications. 2018;28(3):854-64.

53. Csardi G, Nepusz T. The igraph software package for complex network research. InterJournal, ComplexSystems. 2006;1695. Available from: http://igraph.org

54. Guttridge TL, Gruber SH, Krause J, Sims DW. Novel acoustic technology for studying free-ranging shark social behaviour by recording individuals' interactions. Goldstien SJ, editor. PLoS ONE. 2010;5(2):e9324.

55. Heupel MR, Semmens JM, Hobday AJ. Automated acoustic tracking of aquatic animals: Scales, design and deployment of listening station arrays. Marine and Freshwater Research. 2006;57:1-13. 
56. Franklin DC, Legge S, Skroblin A, Heathcote J, Maute K, Schaefer DJ, et al. Wings o tropical finches: interspecific differences in shape are consistent with levels of mobility, but moult and feather fault patterns are more complex. Emu. 2017;117:370-81.

57. Dostine PL, Franklin DC. A comparison of the diet of three finch species in the Yinberrie Hills area, Northern Territory. Emu. 2002;102(2):159-64.

58. Maute KL, French K, Legge S, Astheimer L. Seasonal stress physiology and body condition differ among co-occurring tropical finch species. Journal of Comparative Physiology B: Biochemical, Systemic, and Environmental Physiology. 2013;183(8):1023-37.

59. Johnson DS, Hooten MB, Kuhn CE. Estimating animal resource selection from telemetry data using point process models. McDonald L, editor. Journal of Animal Ecology. 2013;82(6):1155-64.

60. Buderman FE, Hooten MB, Ivan JS, Shenk TM. A functional model for characterising long-distance movement behaviour. Methods in Ecology and Evolution. 2016;7(3):264-73.

\section{Figures}
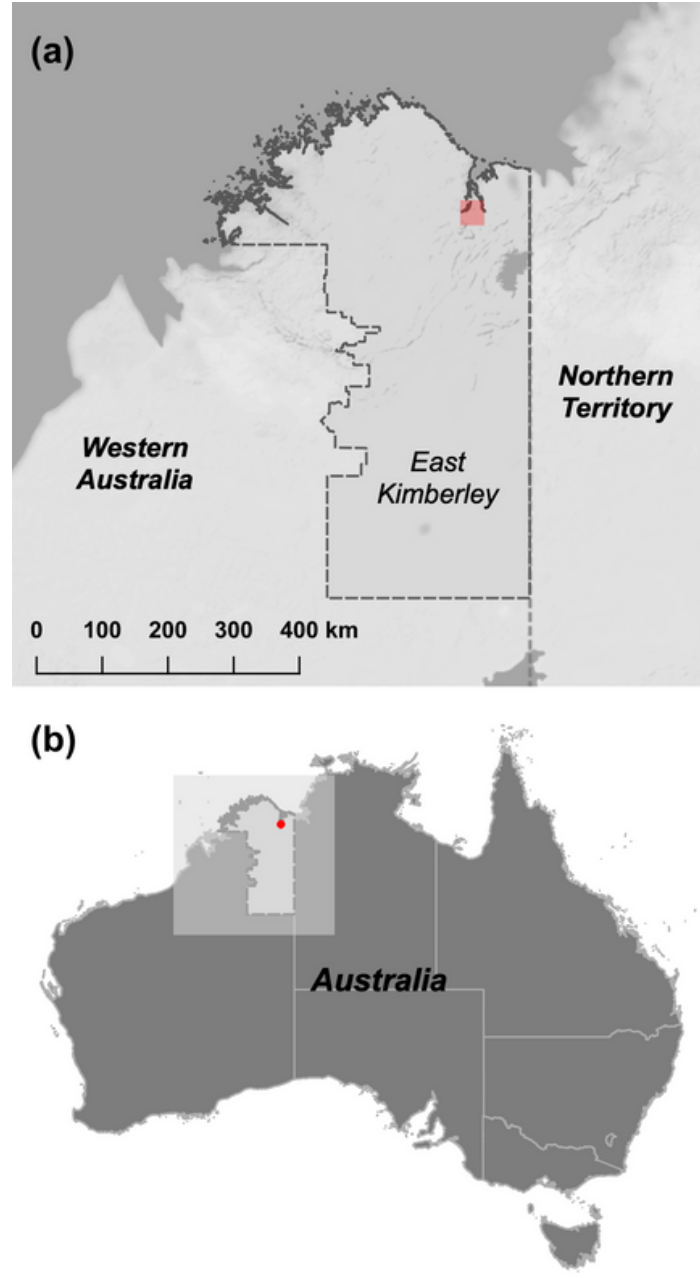

Release Sites

$\Delta$ Receivers

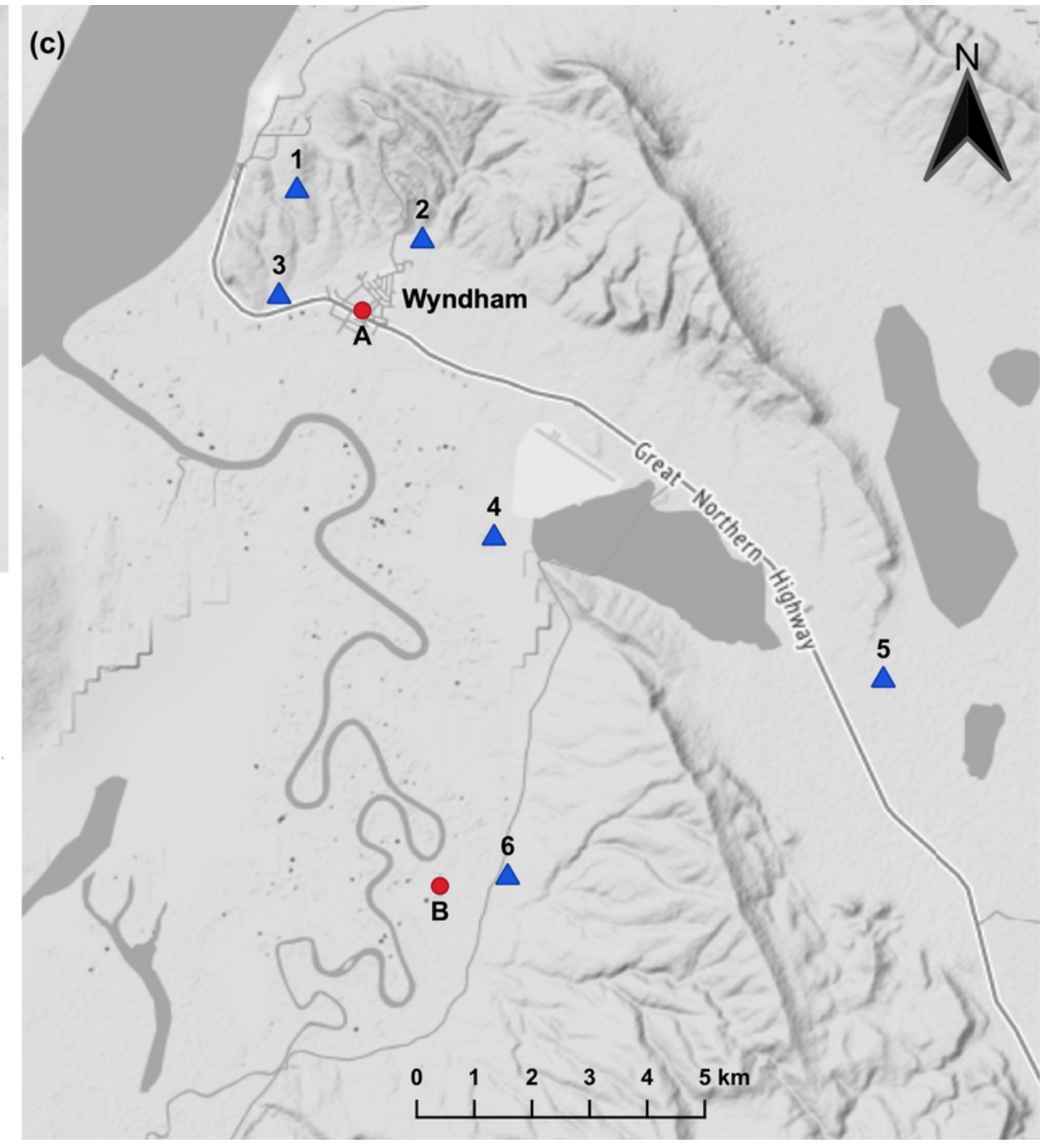

Figure 1 
(a) the East Kimberley Region in Western Australia (WA) (b) The study area (c) the location of receiver stations and release sites surrounding the township of Wyndham, East Kimberley region, WA.

(a)

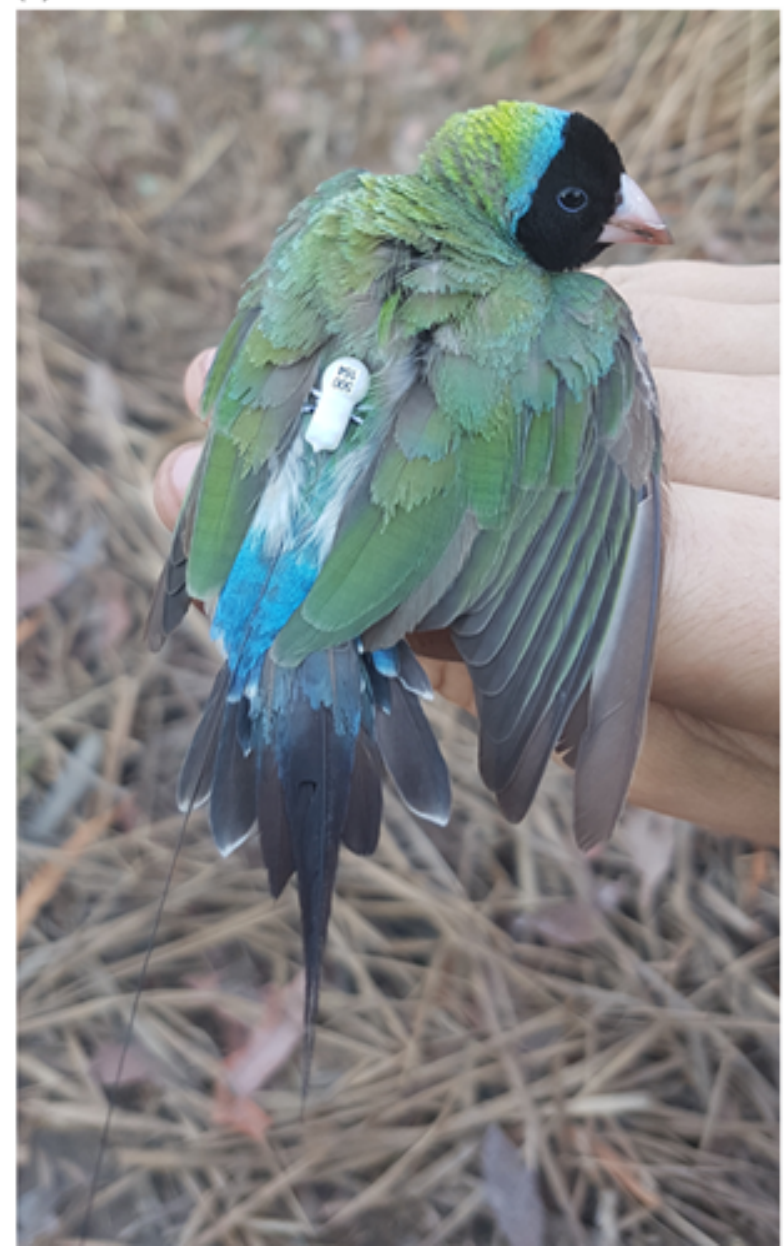

(b)

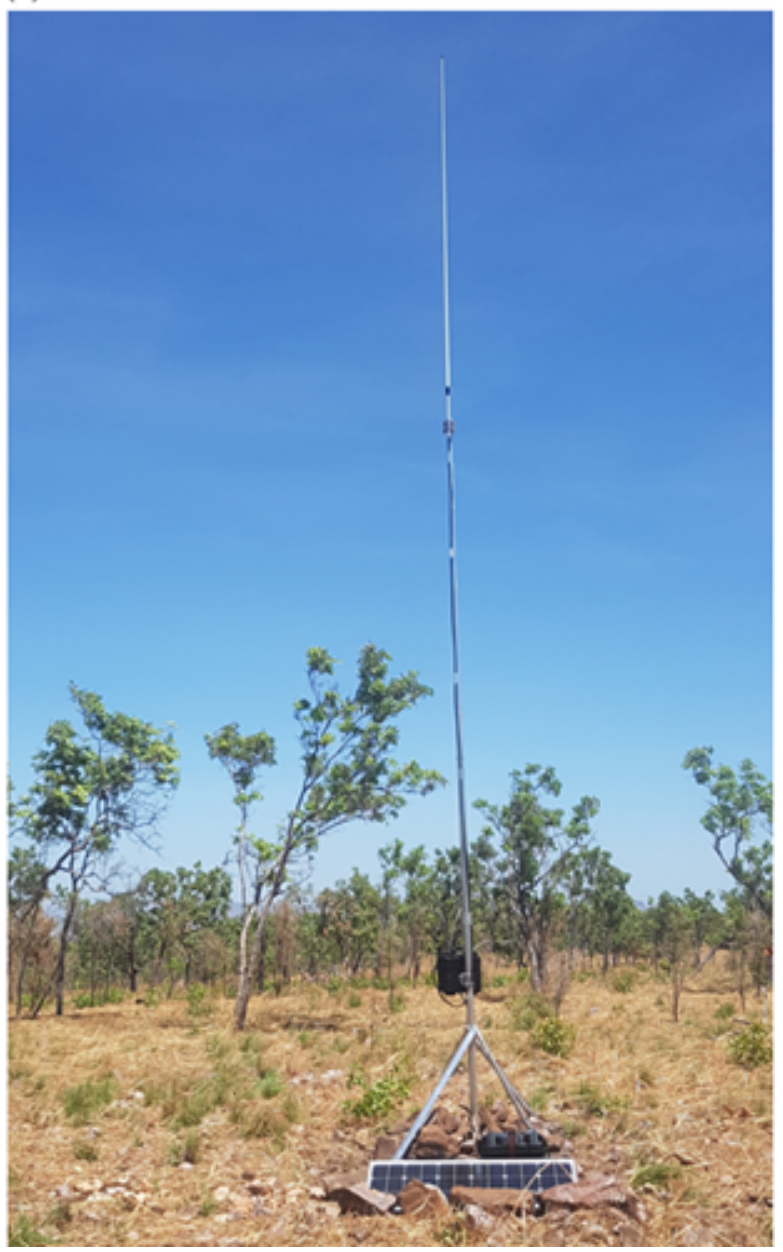

\section{Figure 2}

(a) Black-headed male Gouldian finch tagged with a Lotek Wireless Inc. 0.21 g NTQB2-2 avian coded VHF nanotag; (b) Receiver station set up at the study site. 


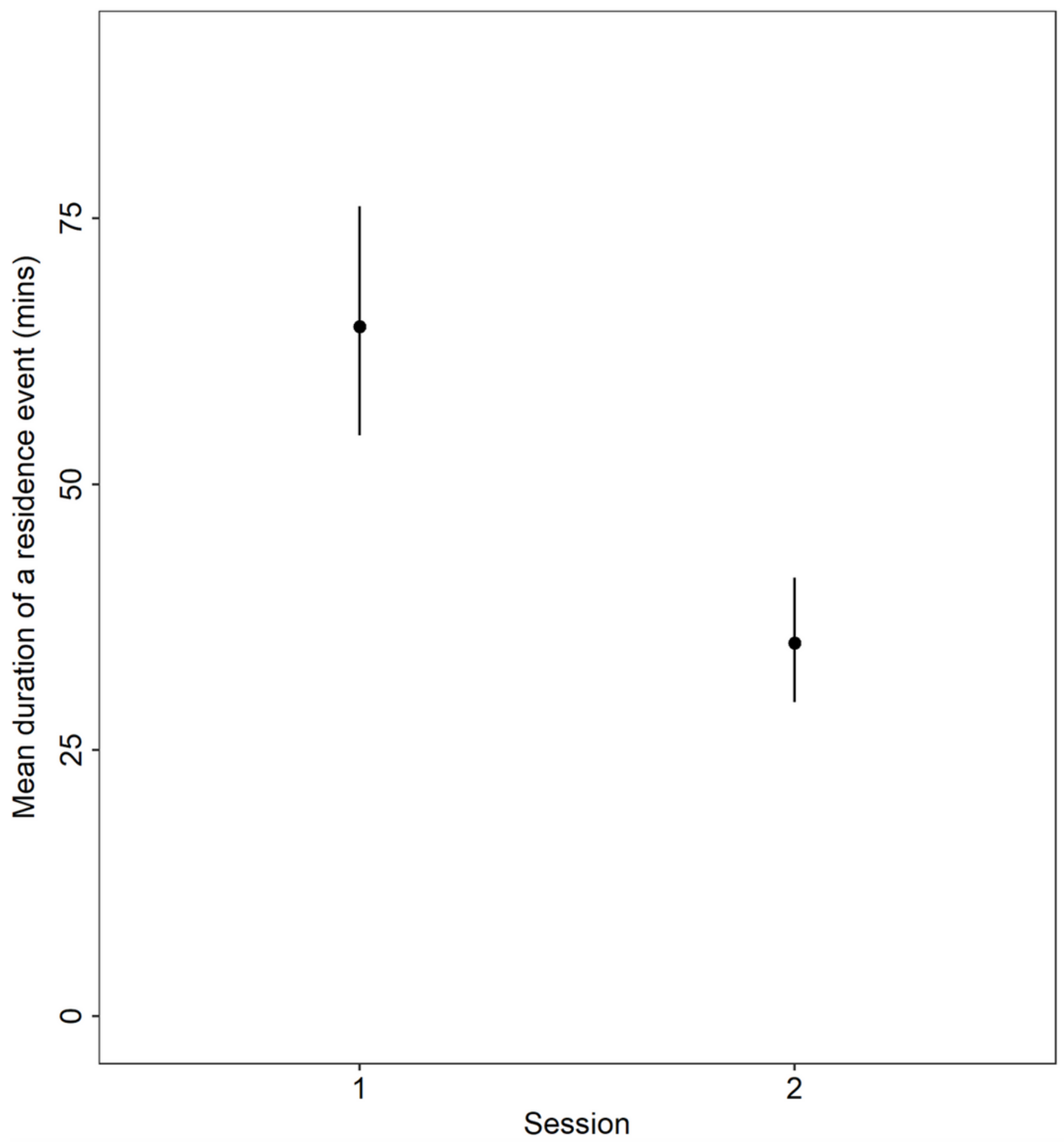

Figure 3

The predicted response in mean residence time from a model that only included session (1 or 2). Error bars represent the standard error of the response variable per individual 
(a)

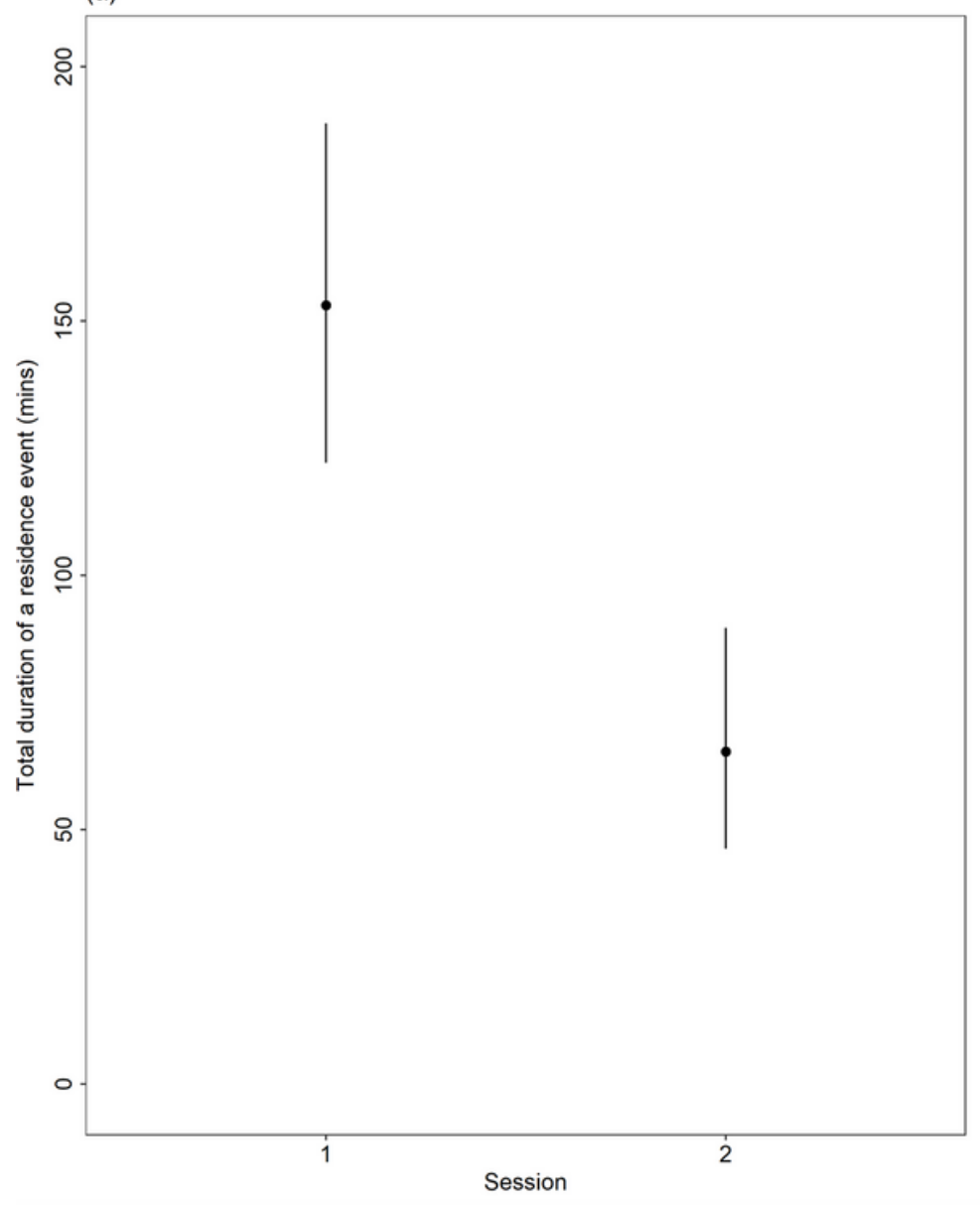

(b)

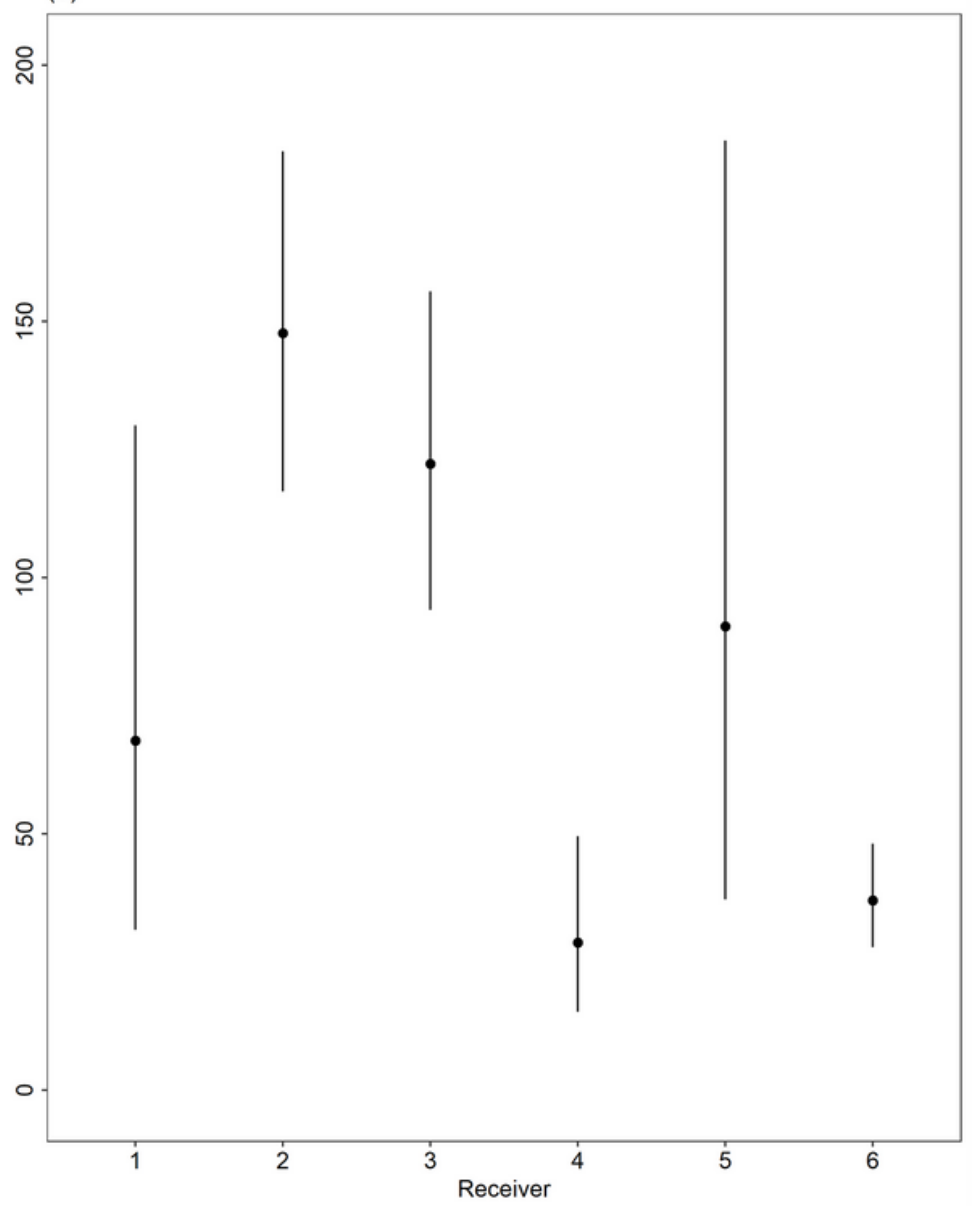

\section{Figure 4}

The predicted response in total residence time from a model that included (a) session (1 or 2), (b) receiver (16). Error bars represent the standard error in the prediction of the response variable per individual. 
(a)

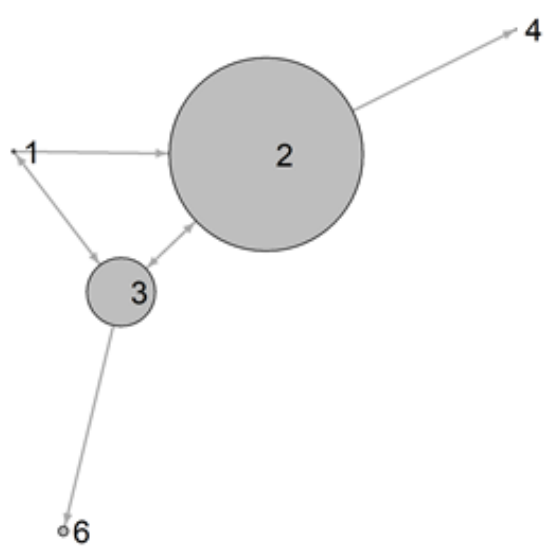

(c)

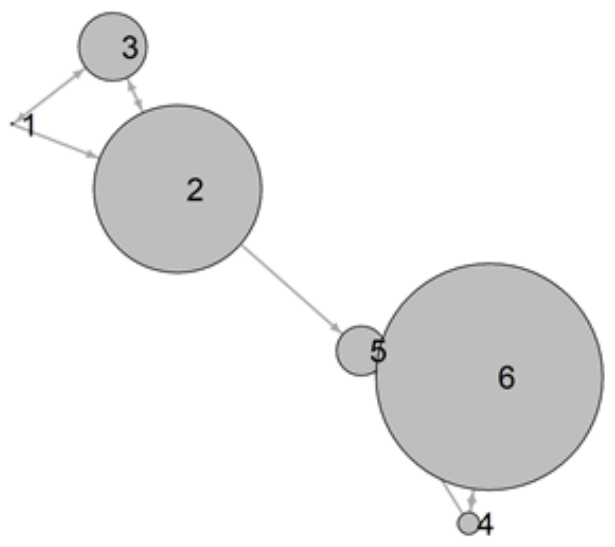

(b)

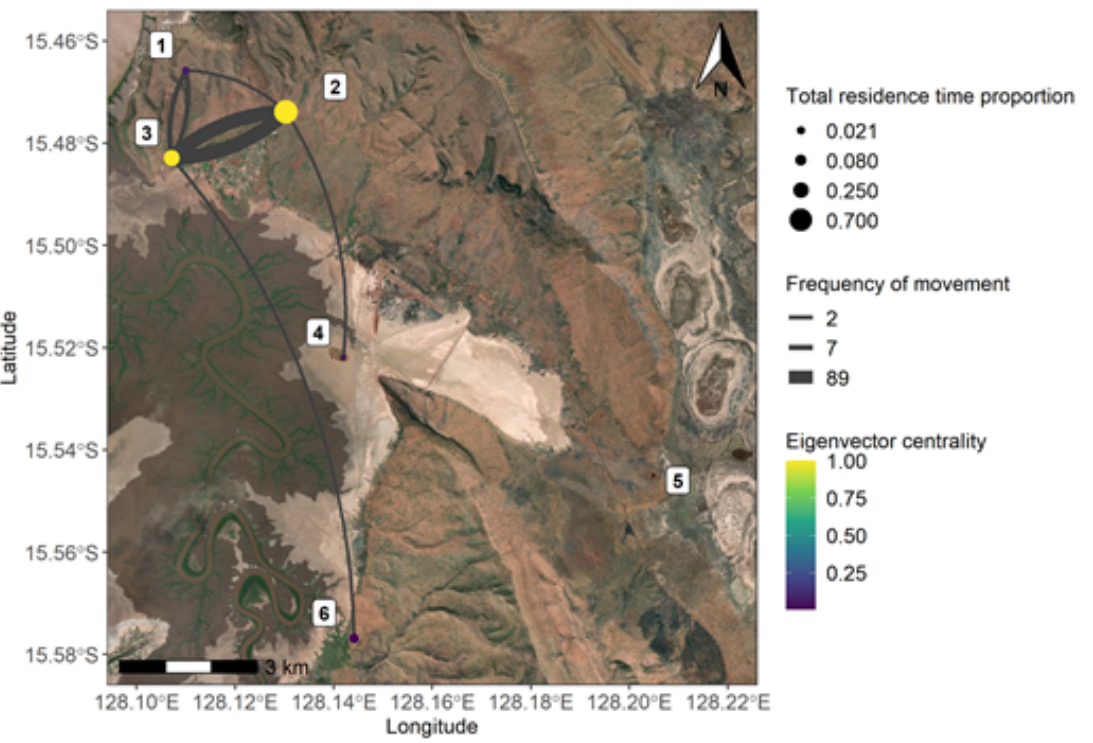

(d)

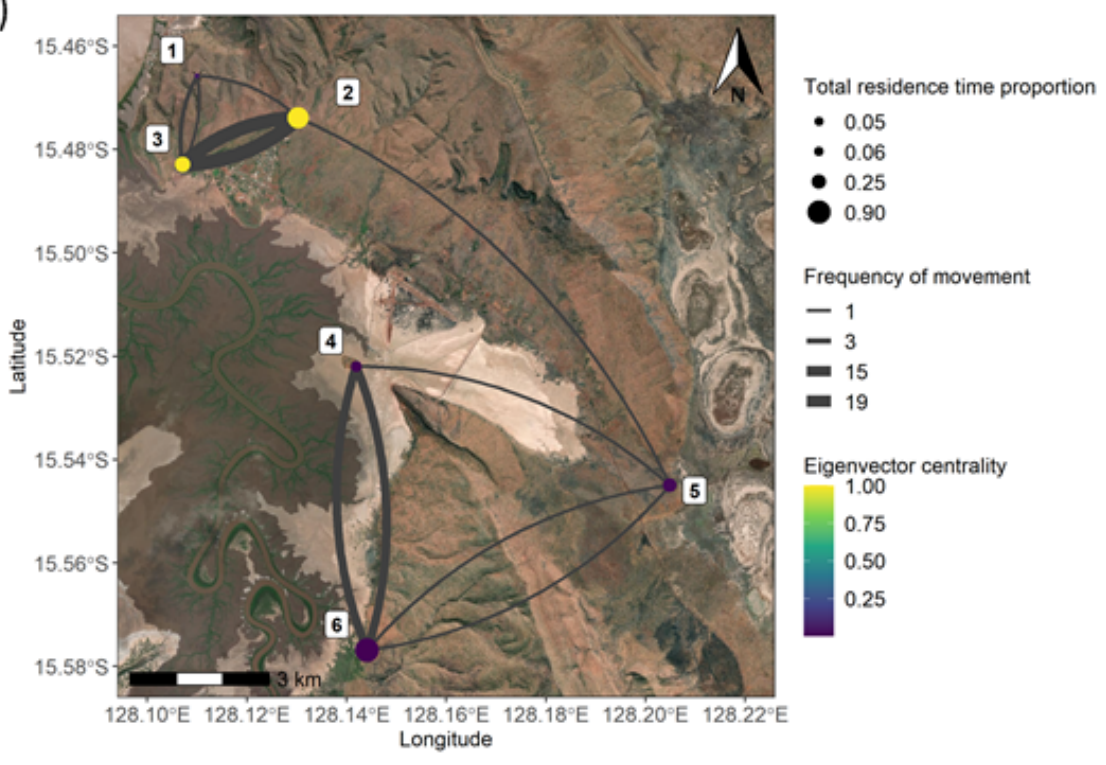

Figure 5

The relative residence time of tagged individuals and their movement between receiver sites in sessions 1 (a, b) and $2(c, d)$. Circles (nodes) represent receivers, and lines (edges) represent pathways between nodes. The circle size denotes the proportional amount of time spent at a receiver of the corresponding receiver. Network graph of the array $(a, c)$. The position of nodes is representative of the centrality of a given node within the network, i.e., how connected that node is to other nodes. Arrows on the lines indicate directional movement. Spatial graph of the network $(b, d)$. Nodes are coloured according to eigenvector centrality. Pathways are clockwise in direction, denoting movement to and from a node. 
(a)

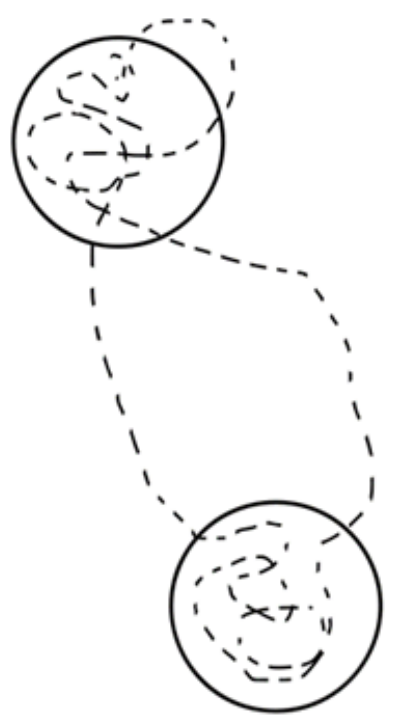

(b)

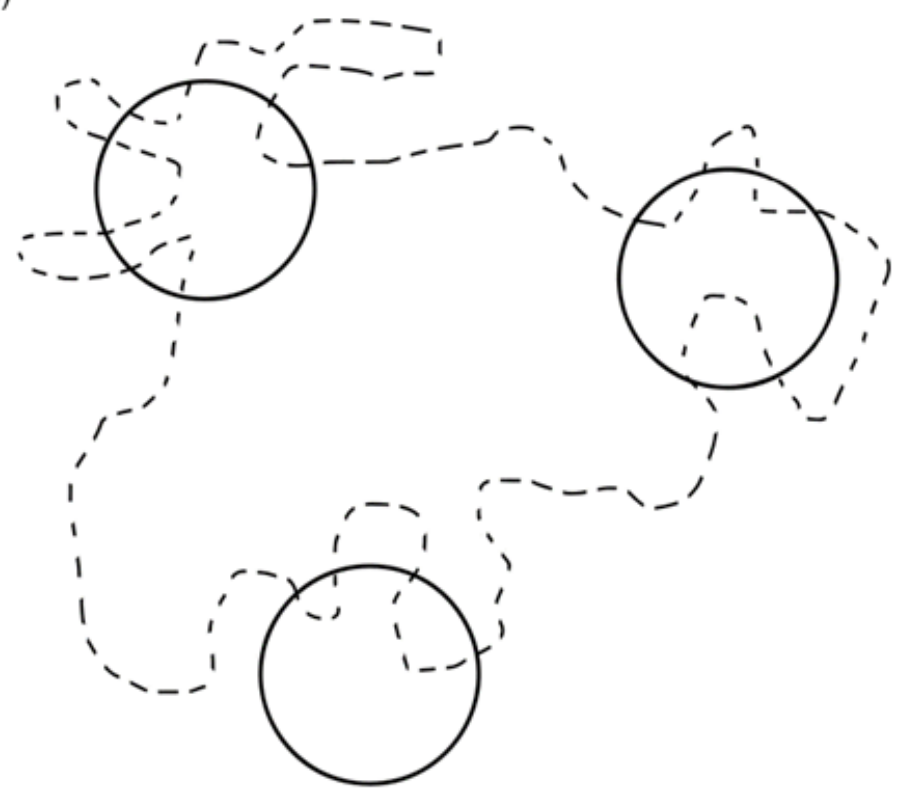

Figure 6

Schematic representation of the two different movement behavioural scenarios provided by the mean or total residence times measures within receiver detection ranges (circles). Mid-dry season movement represented by; a.) High total residence time and high mean residence time indicate high site occupancy and reduced extent of the activity space. b.) Low total residence time and low mean residence time is indicative of low site occupancy and increased extent of the activity space

\section{Supplementary Files}

This is a list of supplementary files associated with this preprint. Click to download.

- AdditionalFile1.docx 